\title{
Chapter 8 \\ Community-Based Mangrove Forest \\ Management in Thailand: Key Lesson \\ Learned for Environmental Risk Management
}

\author{
Surin On-prom
}

\begin{abstract}
This article discusses community-based mangrove forest management and its implications for environmental risk management. The article draws on the case study of Pred Nai village in Trat province, near the Cambodian border in southeast Thailand. The village of Pred Nai has successfully re-forested 1,920 ha of mangrove forests that were previously converted into shrimp aquaculture ponds in the mid1980s. The village has set up a community forest committee and a community resource use regulation and management plan in order to regulate, control, and manage the use of resources by community members. In the process of community mangrove forest management, local villagers have been encouraged to participate in every single step of forest management and planning. It is the active involvement of the local people together with the support of the relevant authorities and national institutions that makes the Pred Nai example a success. The article concludes by pointing out the key lessons learned from community-based mangrove forest initiatives in Pred Nai that can be applied in natural disaster risk management processes.
\end{abstract}

Keywords Community empowerment $\bullet$ Community participation • Communitybased mangrove management

\subsection{Introduction}

In developing countries it is widely recognized that community participation helps to ensure sustainability, makes development activities more effective, and builds local capacity. The participation of local people also ensures equitable benefits for the diverse interest groups within a population as well as ensures effective

\footnotetext{
S. On-prom $(\bowtie)$

Faculty of Forestry, Kasetsart University, Bangkok, Thailand

e-mail: fforsro@ku.ac.th
} 
stewardship. This is partly because communities often have better knowledge and expertise in the management of local resources than government agencies/private industry. Indeed, the involvement of local people in such development business may help reduce government costs. As such, local participation and decentralization are currently being promoted in many developing countries as an alternative approach to development and resource governance. Brown et al. (2002) argue that such a community-based approach often leads to more equitable and sustainable natural resource management. These authors provided a number of reasons to support their argument. One of those reasons concerns the issue of proximity to resources. Those in closest contact with, and whose livelihoods are impacted by, natural resources are best placed to ensure effective stewardship.

Community-based natural resource management (CBNRM) is an approach under which communities become responsible for managing natural resources (forests, land, water, biodiversity) within a designated area. CBNRM gives communities full or partial control over decisions regarding natural resources, such as water, forests, pastures, communal lands, protected areas, and fisheries. The extent of CBNRM control can range from community consultations to joint management or to full responsibility for decision making and benefit collection, using tools such as joint management plans, community management plans, stakeholder consultations and workshops, and communal land tenure rights. Together with decentralization reforms, CBNRM ensures stakeholder participation, increases sustainability, and provides a forum for conflict resolution (World Bank 2006).

In Thailand, participation of local communities in natural resource management has been recognized and promoted by government agencies. Evidence of this is provided by the current National Constitution, which contains some articles giving rights to local people and communities to participate in such state-owned development projects. These local communities currently have a say in decision making processes related to natural resource management. In the forestry sector, the Royal Forest Department (RFD) promotes community forestry projects where local communities living in or adjacent to national reserve forests are given usufruct rights to resources within the community forest areas. The RFD also provides them with technical and financial support. It is worth noting here that the most economically and ecologically successful CBNRM is achieved when community participation is accompanied by the devolution of ownership rights over resources. Once a community has been given tenure over the resources they are helping to manage, they are able to gain benefits from the use of these resources and their interest in participation is naturally increased.

The village of Pred Nai in Thailand's Trat province has successfully re-forested 1,920 ha of mangrove forest that were previously converted into shrimp aquaculture ponds in the mid-1980s. Community conservation of mangrove forests in Pred Nai village emerged without outsider intervention more than 20 years ago. Clearly, the initiative by the Pred Nai villagers qualifies as community-based mangrove forest management and numerous lessons can be drawn from it. The successful implementation of community forestry has reaffirmed the role and significance of a communitybased approach in natural resource management. This community-based approach 
to mangrove management has achieved the twin objectives of restoring coastal and marine biodiversity, and generating income for all socio-economic groups of the village. The initiative has also been able to integrate the marginalized and poor households in the entire process, and tangible benefits are even generated for inhabitants from surrounding villages (Silori et al. 2009).

The aim of this paper is to illustrate the successful case of Pred Nai communitybased mangrove forest restoration and management, and to draw key lessons that can be applied in environmental risk management. Following the introduction, the paper presents the theoretical background to the concept of CBNRM and its implications for sustainable development. It then sets out the case study of Pred Nai village. In conclusion, the paper draws some lessons learned and makes recommendations, as well as offers further research questions.

\subsection{CBNRM and Sustainability: Theoretical Background}

Community-based natural resource management (CBNRM) means different things to different people. The term "CBNRM" not only takes a variety of forms depending on location, or socio-political and bio-physical context, but the term itself is used and interpreted in many different ways (Abensperg-Traun et al. 2011). According to these Abensperg-Traun et al. (2011), the term CBNRM simply describes the management of resources such as land, forests, wildlife, and water by collective, local institutions for local benefits. Following this explanation, the term CBNRM is often associated with programs that (1) are focused on terrestrial wildlife and (2) involve some kind of commercial use of that wildlife in order to generate income for local people.

The World Bank refers to CBNRM as a third alternative to command and control and market-based approaches to natural resource management (World Bank 2006). The term itself has breadth, adaptability, and robustness since it has been described as, inter alia, a tool or a set of tools, a checklist, a method, a set of activities, a model, a process, and an approach (World Bank 2006). At the same time, CBNRM in a particular context is considered to be a problem solving mechanism in land and natural resources. CBNRM is relevant to, and has the potential to provide solutions to, some of the problems found within communal lands.

The importance of CBNRM as an approach has recently been realized. There are at least two reasons explaining what is important about CBNRM (WWF 2006). The first reason concerns the willingness of the state to manage natural resources. In newly independent Southern African countries, for example, the governments did not consider the management of natural resources to be a priority. Financial resources were diverted to other sectors (health, education, and infrastructure development). Military-style methods of enforcing natural resource legislation are also no longer considered appropriate. And the second reason concerns the linkages between natural resources and local livelihoods. Most of the populations in developing countries depend on natural resources for their livelihoods. In Southern Africa, 
for example, most of the population lives in the communal lands. In all communal lands, the harvesting of natural resources plays a significant role in people's livelihoods. This means that strategies and policies to ensure the sustainable management of land and natural resources are important to national economic development. Because of the direct link between people's welfare and the environment, it is important that new approaches and ideas are developed and implemented in natural resource management. The alternative is that people will get poorer and the environmental resources upon which they depend will become scarcer, thereby worsening the already serious poverty trap (WWF 2006).

In addition, CBNRM has been recognized for a long time as a means of promoting safety. CBNRM plays a significant role in promoting a culture of safety by reducing local vulnerabilities and building capacity. Active participation and involvement of communities at the grassroots can make a real difference. This is because through the involvement of local people in the whole process of natural resource management, their feelings and real needs are considered as well as inherent resources. The capacities of local people are enhanced to help them assess situations, identify needs and problems, implement activities, and evaluate outcomes. It can be said that the CBNRM approach emphasizes the involvement of communities, which are at the heart of decision making and implementation of natural resource activities and management.

The links between CBNRM and the issue of resilience were observed and studied. The existing literature on resilience in social-ecological systems strongly suggests that community-based institutions may play a key role in fostering the resilience of communities and the ecosystems they inhabit. Some suggest that local management institutions enhance resilience. One reason is because management practices are locally adapted and based on local ecological knowledge (WWF 2006). More importantly, however, some CBNRM organizations promote social learning, an intentional process of collective self-reflection through interaction and dialogue among diverse participants. Social learning is promoted in part due to CBNRM groups' attention to monitoring and adaptive management, and their emphasis on learning and education. As rural communities face increasing environmental stresses as well as unpredictable economic and political shocks, the ability to learn and adapt is critical to their sustainability and resilience (WWF 2006).

It can be concluded that, through CBNRM, the community is not only the beneficiary but also the main actor in every step of the forest resource management process. The involvement of the community is important to ensure sustainability. The information collected will be more relevant and will reflect the opinions and realities of community members, particularly the vulnerable and poor. The capacity (self confidence, knowledge, skills such as team work, planning, etc.) of the entire community to deal with different situations they face will be developed. Natural forest resource management and community development activities and programs will achieve better, more practical and effective results. Community life will become more stable and sustainable. 


\subsection{Pred Nai Community-Based Mangrove Forest Management}

This section presents the case study of Pred Nai villagers and their efforts to conserve mangrove forests. This community-based organization was founded in the mid-1980s to reverse the effects of destructive mangrove logging near the coastal village of Pred Nai. A parallel goal was the recovery of local crab populations, which are an important source of income for poorer members of the village. The success of Pred Nai villagers in restoring the mangrove ecosystem made the group into a model and point of reference for policy reforms that aim to transfer authority to forest communities.

The village of Pred Nai is located in Trat Province on the eastern seaboard of Thailand. The geographical area of the village is 378.7 ha, of which the inhabited area covers nearly $42 \%$, while the remaining area is under agriculture and other land use practices. The area of community-managed mangrove forest, one of the last surviving mangrove forests in Thailand's eastern seaboard, is spread over approximately 12,000 rai $(1,920 \mathrm{ha})$, about $1 \mathrm{~km}$ to the west of the village. The mangrove forest is regularly inundated by 12 major and 6 minor creeks (Fig. 8.1).

Pred Nai village was founded in the 1850 s by about $8-10$ households. In 2009 it was reported that the population of Pred Nai village had increased to 560 people or nearly 130 households. The majority of the households own land, though most of

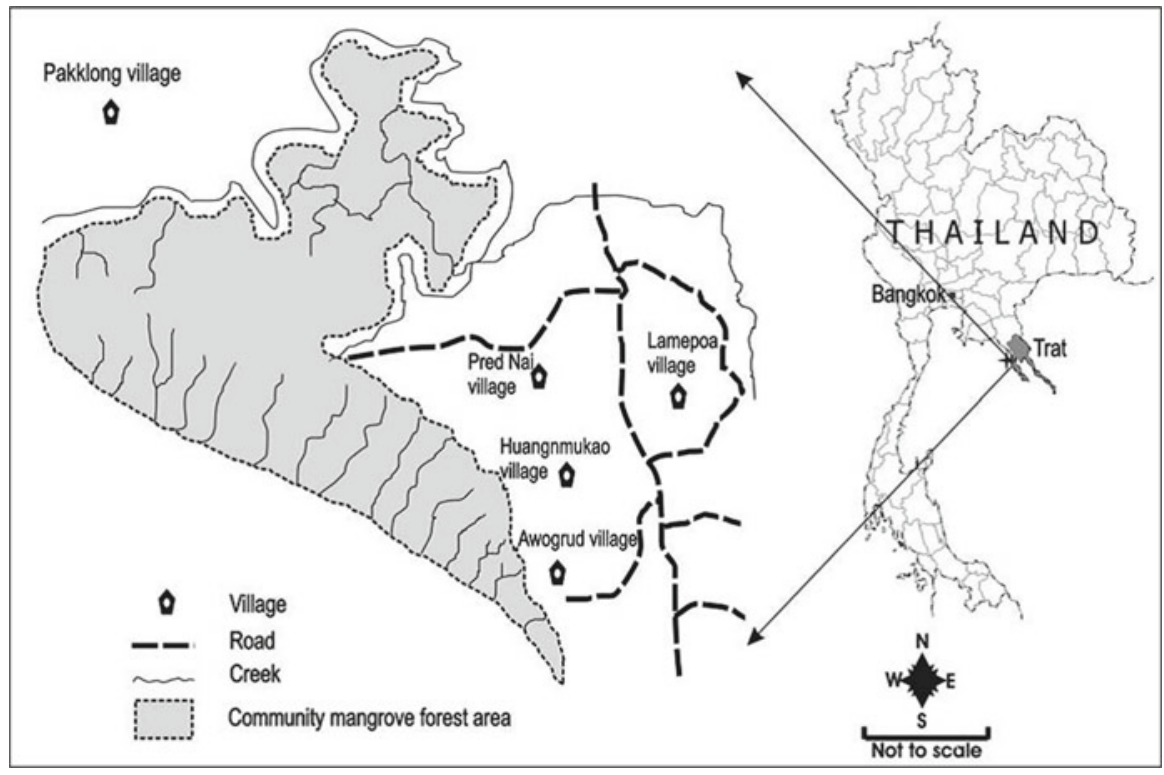

Fig. 8.1 Pred Nai village map (Source: Silori et al. 2009) 
them have marginal to small holdings. Only around $7 \%$ of the households do not own land. The agriculture land use is dominated by rubber plantations and orchards of durian, rambutan, jackfruit, mango, and mangosteen. Fish and shrimp farming is another major land-use practice in the village. Small and marginal land holders also work for daily wages in the agricultural sector, while a sizeable number of households venture into the mangroves to collect various marine animals for home consumption and for sale such as grapsoid crab (Metopographus sp.), mud crab (Scylla serra), and shrimps, as well as a variety of fish and shells.

Agriculture and daily wage labor in the agricultural sector, fish and shrimp farming, and collection of marine products from mangroves were reported as major income sources by the villagers. Silori et al. (2009) claimed that the average annual income of Pred Nai villagers ranged from about THB 65,000 (USD 1,914) for landless households to slightly above THB 1million (USD 30,531) for a large land holder, averaging about THB 435,000 (USD 12,809) per annum. Fish and shrimp farming contributed up to $63 \%$ to the average annual income, followed by agriculture (26\%), and collection of marine animals (mainly grapsoid crab) (9\%). The remainder was made up of other activities such as collection of honey and agro-tourism. Thus, nearly $74 \%$ of the total average household income can be directly or indirectly attributed to mangrove and marine resources (Silori et al. 2009).

The mangroves of Pred Nai were placed under a logging concession in 1941. Uncontrolled logging and intensive shrimp farming caused heavy destruction. As a result, an area of nearly 48,000 ha of mangroves was reduced to 1,920 ha by the early 1980s (Silori et al. 2009). Government concessions favored corporations and restricted the villagers from harvesting crabs, shellfish, and other mangrove resources. Some local people converted degraded mangrove areas into shrimp farms and built gates to block seawater. This activity further damaged the mangrove ecosystems and availability of crabs and other marine animals decreased. Other illegal activities such as timber harvesting and hunting of birds and other wild animals further degraded the biodiversity of the mangroves. Rapid depletion of mangroves and marine resources directly threatened the livelihoods of the local villagers and they therefore decided to stop the degradation process. A 'core group' of 5-10 villagers started to resist the corporate destruction of the mangroves, and their resistance rapidly gained momentum and support from the rest of the villagers, intensifying demands to stop the logging. The struggle of the villagers paid off and commercial logging was stopped in 1987 by the Government. The logging companies were ousted from the area and the sea water gates were destroyed to allow the flooding of the degraded mangroves. This was an important incentive for the villagers to institutionalize the struggle of the core group and they formed a village level group called Pred Nai Community Forestry Group (PNCFG) in 1987. In due course, the PNCFG was supported by local and provincial governments and also by donor and technical agencies. The Regional Community Forestry Training Centre for Asia and the Pacific (RECOFTC), for example, was one of the main technical support organizations, and assisted in the formulation of a mangrove restoration and management plan following a participatory approach.

Since its emergence the PNCFG has conducted various activities to regenerate the mangrove forests. The group initially developed a forest management plan that 
produced intensive mapping of forest resources and instituted forest patrols to prevent illegal logging and charcoal production. Also, the group initiated tree-planting activities in degraded mangrove areas. Over time, some stands have begun to regenerate naturally. Since 1993, the Pred Nai initiative has focused on the sustainable management of marine resources and ecological monitoring within the mangrove forests. In 1997, the group introduced some regulations on crab harvesting. These rules specified the suspension of harvesting during the crab breeding period in October (UNDP 2012).

In parallel with the conservation activities, the PNCFG also initiated a village community fund with the help of a local monk, primarily with the objective of introducing the concept of financial sustainability of community initiatives. Under this initiative, the villagers were encouraged to save part of their income and earn some interest, while at the same time keeping the savings within the village so that the funds could be loaned to other needy households. Later, this initiative won the support of government agencies and NGOs, obtaining donations from international agencies and local institutions such as the Social Investment Fund (SIF), the Thailand Research Fund, the Education Institute, and even from political parties. The village common fund has total savings of more than THB 3 million at present, and regularly receives contributions from crab catchers, local traders, and also from agro-tourism activities, and thus it is sustained year after year (Silori et al. 2009).

Over nearly three decades the capacity of the PNCFG has been strengthened through various training programs provided by many organizations. RECOFTC has been one of the key organizations among these. It has been associated with the PNCFG since 1999 and helped to promote the PNCFG's outreach to communities both within and outside of Thailand. It has also encouraged the exchange of ideas about sustainable utilization of natural resources among the villagers. As a result, the PNCFG has taken the lead in building a network of more than 20 village-level community forestry groups along the four provinces at the eastern seaboard of Thailand to manage mangrove resources. Not only this, but Pred Nai has also received international attention for its contributions in the community forestry sector. Besides attracting a number of study tours from many countries, the PNCFG received the Green Globe Award in 2001 and was nominated for the Equator Initiative award in 2004 (Senyk 2005). According to the villagers, the capacity of the PNCFG to manage the resources, regulate their access and use, and resolve conflicts has increased. At the same time, the relationship with the key government departments, such as the Department of Fisheries, the Tambon (Sub district) Administrative Office (TAO), and the Department of Marine and Coastal Resources (DMCR) has improved. Villagers interact regularly during monthly village meetings. Awareness of the importance of mangrove forests and their conservation has been raised. Also, key government officials are involved in formal and informal village meetings and capacity building activities, and help in conflict negotiations, if any.

There can be no doubt that the conservation efforts of the Pred Nai villagers and the PNCFG have had a direct impact on restoring biodiversity, alleviating poverty, and facilitating local economic development. The chief biodiversity impact has been the restoration and protection of 1,920 ha of coastal mangrove forest (UNDP 2012). This substantial regeneration of mangrove forest cover has enabled the return 
of wildlife species to the coastal area. It was reported that stocks of crab, shellfish, and fish had all increased (Silori et al. 2009). The restoration and conservation of mangrove forests also improves the long-term sustainability of the villagers' economic activities. The household income patterns clearly reflect the importance of coastal and marine resources in the livelihood strategies of the local residents, especially the poor ones. This is further substantiated by the trends in the number of villagers who venture into the mangroves to collect marine animals, particularly mud crabs. About a decade ago, 6-7 people used to venture into the mangroves every night to collect crabs. This number at present has grown to nearly 70 . More important, however, is the fact that, despite such a steady increase in the number of crab collectors, the average quantity of crabs per visit for each collector has not declined over time. It stands at around 7-8 kg, while the time spent has declined significantly to an average of $4-5 \mathrm{~h}$ per night at present, as compared to almost a whole night 10 years ago (Silori et al. 2009; Somsak et al. 2004).

In conclusion, the steady growth of conservation and development activities in Pred Nai since the mid-1980s is testament to the activities' resilience and the broadbased support they receive from villagers and various development agencies. Meanwhile, the substantial management capacity developed through the PNCFG ensures that the initiative is well-equipped to sustain its impact over time.

\subsection{Discussion}

In this final section, an attempt will be made to summarize the lessons learned from the Pred Nai case study that may be relevant to and apply in the sustainability of disaster risk management. As is widely recognized, disaster management is a pressing issue for all of us and should be undertaken on a comprehensive basis. Such an approach to natural disaster risk management should engage, involve, and empower communities so that community members can cope with the adverse effects of natural hazards. And the most effective approach for achieving sustainability in dealing with uncertainties and risks at a local level is the establishment of resilient communities. The major lessons drawn from Pred Nai village are as follows.

The case of Pred Nai suggests that sustainability of development programs (mangrove rehabilitation and conservation in this case) by a community largely depends on the benefits that can be generated and the local people's participation. If they understand and recognize the significance of the mangrove forest and the benefits that can be generated from activities related to it, the community will step in and take part. This case also made us realize that the community-based management process was based on local people's participation, initiated by a group of villagers who started to provide others with relevant information about the destruction of the mangrove forest and marine life. These people instigated popular awareness of the responsibility of everyone in the community—not just certain people - to rely on themselves collectively, without the need to wait for an agency to come in to provide assistance. If the community does not act to solve a problem right away, such problems eventually impact livelihoods. If a community can mobilize its partners, 
however, they can contribute to achieving the same goals of protecting the resources and preventing them from being destroyed. Often the necessary participation can be achieved through the representative systems of the group or the committee that has been mandated to deal with or to make decisions on such issues as quickly as possible.

A community-based approach is a critical factor in sustainable development at community and national levels. The most common elements of a community-based approach are participation, partnership, empowerment, and ownership by local people. The emphasis of sustainable natural resource management should focus on local communities and the people who live in or adjacent to them. Unless the conservation and development efforts are sustainable at individual and community level, it is difficult to achieve the goal of sustainability. However, there need to be opportunities for the poor and "marginalized groups" in the village to be involved from the initial programming stage of conservation and development activities. In the case of Pred Nai, for example, the poor were allowed to participate in the process of formulating harvesting regulations. Through the community-based activities, these marginalized groups should be able to participate alongside community organizations like PNCFG, government officials, experts, and NGO workers as the key stakeholders.

Partnership development and institutional linkages on all horizontal and vertical levels are critical to achieve the sustainability of conservation and development activities. As we observed from Pred Nai, the PNCFG has incorporated innovative partnerships and a wide range of participants. At local level, the group has networked with several villages to enable dialogue with those stakeholders in coastal and marine resources and also to ensure broad support for sustainable harvesting in the mangrove forests. Moreover, the group has gained experience in working collaboratively with outsiders such as RECOFTC, fishery experts, and foresters. Relationships with outside institutions and organizations have also been important for helping the group to overcome funding and technical challenges to implement projects. The provincial governor became an active supporter of Pred Nai's initiatives. More importantly, the group has been working with Tambol Administrative Organization (TAO), the elected local government body, in order to formalize regulations on coastal and marine resource harvesting.

It is worth making the generalization here that community-based approaches and empowerment of communities help to achieve sustainability in conservation and development. However, CBNRM efforts need technical, financial, and institutional support. Institutionalizing the community can result in more sustainable development programs.

\subsection{Conclusion}

In order to ensure more efficient CBNRM, this paper recommends: (1) legalizing the status of community-based organizations like PNCFG in order to enhance their capacity to make decisions concerning natural resource uses and allocations; 
(2) providing necessary support for Local Government Organizations LGOs to ensure that they can identify effective and sustainable mangrove forest management strategies through the process of local people's participation; (3) compiling and managing knowledge, experience, and innovation emerging from community mangrove forest management for use in education, learning, and dissemination to other interested communities and individuals; and (4) developing an effective monitoring and evaluation system for community mangrove forest management.

Open Access This article is distributed under the terms of the Creative Commons Attribution Noncommercial License which permits any noncommercial use, distribution, and reproduction in any medium, provided the original author(s) and source are credited.

\section{References}

Abensperg-Traun M, Roe D, O'Criodain C (eds) (2011) CITES and CBNRM. In: Proceedings of an international symposium on "The relevance of CBNRM to the conservation and sustainable use of CITES-listed species in exporting countries," Vienna, Austria, 18-20 May 2011. Gland, Switzerland: IUCN and London: IIED

Brown D, Malla Y, Schreckenberg K, Springate-Baginski O (2002) Community forestry, from supervising 'subjects' to supporting 'citizens': recent developments in community forestry in Asia and Africa. Natural Resource Perspectives 75. Overseas Development Institute (ODI), London

Senyk J (2005) Lessons from the Equator Initiative: community based management by Pred Nai Community Forestry Group in the mangroves of Southeastern Thailand. http://www.umanitoba.ca/institutes/natural_resources/pdf/Tech\%20Report\%20Thailand\%2 0-\%20Jason\%20 Senyk.pdf

Silori CS, Soontornwong S, Roongwong A, Enters T (2009) Links between biodiversity conservation and livelihood security in practice: a case study of community conservation of mangroves in Pred Nai, Thailand. Final draft manuscript for Community Forestry International workshop, September 15-18, 2009, RECOFTC, Pokhara

Somsak S, Worrapornpan S, Kaewmahanin J (2004) Biodiversity management and poverty alleviation by Pred Nai community forest, Trad province, Thailand. Ferng-fah Printing Company Limited, Bangkok

United Nations Development Programme (2012) Pred Nai mangrove conservation and development group, Thailand. Equator Initiative Case Study Series, New York

World Bank (2006) Agriculture investment sourcebook. http://www.worldbank.org

WWF (2006) The community-based natural resource management manual. Wildlife Management Series. World Wide Fund for Nature, Harare, Zimbabwe 